\title{
EchoGéo
}

11 | 2010

Madagascar

\section{Les Cocotiers de la France : tourismes en Outre-mer} Ouvrage de Jean-Christophe Gay

\section{CpenEdition}

\section{Journals}

Édition électronique

URL : https://journals.openedition.org/echogeo/11629

DOI : 10.4000/echogeo.11629

ISSN : 1963-1197

\section{Éditeur}

Pôle de recherche pour l'organisation et la diffusion de l'information géographique (CNRS UMR 8586)

\section{Référence électronique}

"Les Cocotiers de la France : tourismes en Outre-mer », EchoGéo [En ligne], 11 | 2010, mis en ligne le 24 février 2010, consulté le 31 juillet 2021. URL : http://journals.openedition.org/echogeo/11629 ; DOI : https://doi.org/10.4000/echogeo.11629

Ce document a été généré automatiquement le 31 juillet 2021.

EchoGéo est mis à disposition selon les termes de la licence Creative Commons Attribution - Pas d'Utilisation Commerciale - Pas de Modification 4.0 International (CC BY-NC-ND) 


\title{
Les Cocotiers de la France : tourismes en Outre-mer
}

\author{
Ouvrage de Jean-Christophe Gay
}

1 Diversité des territoires ultramarins, diversité des formes de tourisme.

2 Au-delà du mythe océanien qui assimile cocotiers, soleil, plages de sable blanc et farniente, Jean-Christophe Gay étudie la production de ces espaces touristiques et met en évidence le faible développement de ce secteur d'activité, au regard des atouts et des investissements dont bénéficient globalement les territoires d'outremer.

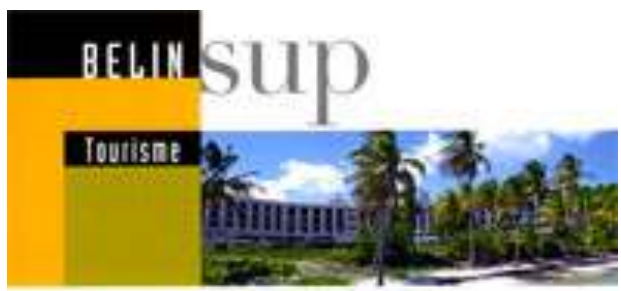

\section{Les cocotiers}

de la France

Tourismes en otutremer

3 Son ouvrage se compose de trois grands chapitres :

- le tourisme ultramarin d'hier à

aujourd'hui

- les systèmes touristiques

- le tourisme en ces lieux.

4 Dans une perspective historique, l'auteur analyse une trentaine de documents:

tableaux statistiques, graphiques, photographiques, qui permettent de suivre l'évolution comparée de la fréquentation régionale depuis la période coloniale jusqu'à nos jours.

Le deuxième chapitre met en évidence un système domien et un système pacifique.

6 Le premier, basé sur la départementalisation de 1946, a privilégié une forme de tourisme « affinitaire ». En effet, une grande partie des touristes des DOM, ont des liens familiaux ou amicaux avec ces territoires. Ils n'utilisent pas les prestations commerciales usuelles : agences, hôtels, croisières. Après une période faste entre 1970 
et 1980, grâce aux investissements publics, la fréquentation hôtelière est en crise aux Antilles et à la Réunion dès 2000. Le parc hôtelier vieillissant se renouvelle peu, les établissements construits en copropriété, sous la loi Pons, sont vendus ou loués partiellement par leurs détenteurs, et compensent la pénurie locale de logements. Les groupes hôteliers internationaux se défient de ces destinations et investissent dans des iles proches ou présentant les mêmes avantages touristiques: Maurice, Seychelles. La desserte aérienne insuffisante représente un facteur aggravant. Les flux entre la métropole et les DOM correspondent à un type de fréquentation essentiellement saisonnier et affinitaire, et on observe peu de tourisme d'agrément ou d'affaires, peu de liaisons régionales.

7 Le système Pacifique concerne surtout la Polynésie et la Nouvelle Calédonie. Les TOM, bien que subventionnés, bénéficient d'une large autonomie par rapport à la métropole. Le mythe des «îles paradisiaques» y joue au maximum. Les grandes chaines internationales sont présentes mais l'ouverture ou la fermeture des lignes aériennes explique les variations de la fréquentation. L'éloignement de l'Europe et le coût de la vie limitent l'essor du tourisme aux classes aisées, américaines et japonaises. Parallèlement se développe en Nouvelle Calédonie la multi résidentialité. Des retraités métropolitains, migrants temporaires, vont s'y installer et demeurer à la faveur de conditions fiscales avantageuses.

Des disparités apparaissent entre les pays qui composent ces systèmes.

9 La dernière partie de l'ouvrage porte sur l'étude du phénomène touristique selon les lieux. Après avoir rappelé que «le goût actuel pour certains paysages est une construction sociale » l'auteur s'interroge sur " les dynamiques spatiales à l'œuvre, et leurs implications en termes de développement des territoires".

10 A partir d'exemples choisis dans les DOM, dans l'aire pacifique, dans des pays tels que la Guyane, les archipels de l'océan indien ou atlantique, il dresse une typologie des formes régionales de tourisme.

11 Les lieux privilégiés du tourisme ultramarin: Saint Barthélemy, Saint Martin, BoraBora font l'objet d'un examen plus approfondi de leur situation actuelle et des perspectives économiques ouvertes par cette activité dans les prochaines années. Bernadette Joseph

\section{BIBLIOGRAPHIE}

Les Cocotiers de la France : tourismes en Outre-mer, Gay Jean-Christophe. Paris : Belin, 2009, 135 p. , XVI pl. (Collection Belinsup tourisme). 